\section{OPEN ACCESS}

Edited by:

Harry Pantazopoulos,

McLean Hospital, United States

Reviewed by:

Jaewon Ko,

Daegu Gyeongbuk Institute of Science and Technology (DGIST), South Korea

Alexander Dityatev, German Center for Neurodegenerative

Diseases (HZ), Germany

*Correspondence:

Larisa M. Haupt

larisa.haupt@qut.edu.au

Received: 20 August 2017 Accepted: 25 September 2017 Published: 17 October 2017

Citation:

Yu C, Griffiths LR and Haupt LM (2017) Exploiting Heparan Sulfate Proteoglycans in Human Neurogenesis-Controlling Lineage Specification and Fate.

Front. Integr. Neurosci. 11:28. doi: 10.3389/fnint.2017.00028

\title{
Exploiting Heparan Sulfate Proteoglycans in Human Neurogenesis-Controlling Lineage Specification and Fate
}

Chieh Yu, Lyn R. Griffiths and Larisa M. Haupt*

Genomics Research Centre, Institute of Health and Biomedical Innovation, School of Biomedical Sciences, Queensland University of Technology, Brisbane, QLD, Australia

Unspecialized, self-renewing stem cells have extraordinary application to regenerative medicine due to their multilineage differentiation potential. Stem cell therapies through replenishing damaged or lost cells in the injured area is an attractive treatment of brain trauma and neurodegenerative neurological disorders. Several stem cell types have neurogenic potential including neural stem cells (NSCs), embryonic stem cells (ESCs), induced pluripotent stem cells (iPSCs), and mesenchymal stem cells (MSCs). Currently, effective use of these cells is limited by our lack of understanding and ability to direct lineage commitment and differentiation of neural lineages. Heparan sulfate proteoglycans (HSPGs) are ubiquitous proteins within the stem cell microenvironment or niche and are found localized on the cell surface and in the extracellular matrix (ECM), where they interact with numerous signaling molecules. The glycosaminoglycan (GAG) chains carried by HSPGs are heterogeneous carbohydrates comprised of repeating disaccharides with specific sulfation patterns that govern ligand interactions to numerous factors including the fibroblast growth factors (FGFs) and wingless-type MMTV integration site family (Wnts). As such, HSPGs are plausible targets for guiding and controlling neural stem cell lineage fate. In this review, we provide an overview of HSPG family members syndecans and glypicans, and perlecan and their role in neurogenesis. We summarize the structural changes and subsequent functional implications of heparan sulfate as cells undergo neural lineage differentiation as well as outline the role of HSPG core protein expression throughout mammalian neural development and their function as cell receptors and co-receptors. Finally, we highlight suitable biomimetic approaches for exploiting the role of HSPGs in mammalian neurogenesis to control and tailor cell differentiation into specific lineages. An improved ability to control stem cell specific neural lineage fate and produce abundant cells of lineage specificity will further advance stem cell therapy for the development of improved repair of neurological disorders. We propose a deeper understanding of HSPG-mediated neurogenesis can potentially provide novel therapeutic targets of neurogenesis.

Keywords: heparan sulfate proteoglycan, stem cell, neurogenesis, syndecan, glypican, perlecan, growth factors, biomimetics 


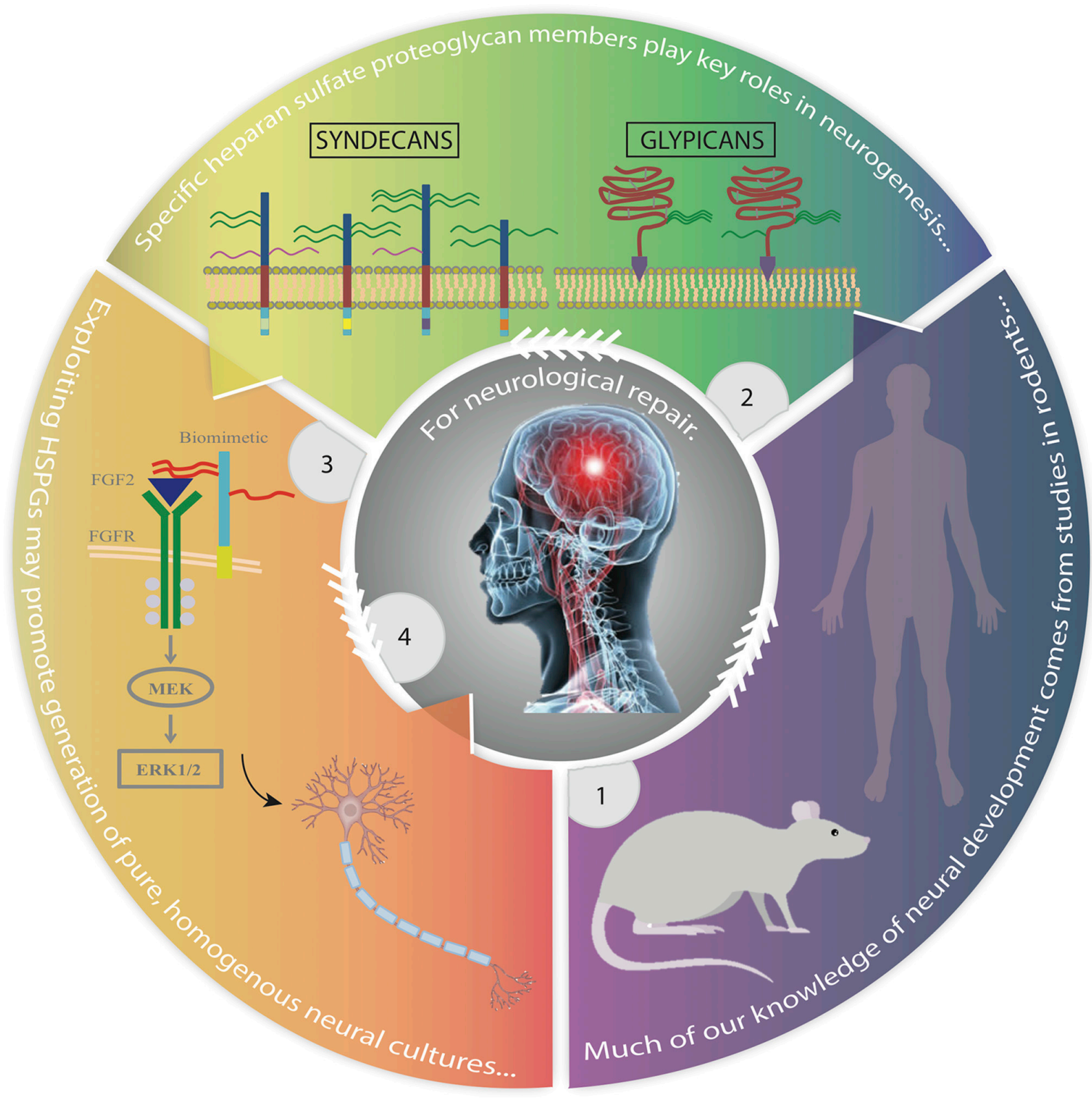

GRAPHICAL ABSTRACT | Advances in the study of mammalian neural development identifying heparan sulfate proteoglycans as key regulators that may be exploited to improve stem cell replacement therapy. Panel 1. Most of our current knowledge of human neural development is derived from studies in rodents. Panel 2. HSPGs, particularly membrane-bound syndecans and glypicans, are major regulators of neurogenesis. Panel $\mathbf{3}$. Exploiting the role of HSPGs in mediating stem cell fate through use of biomimetics, growth factor-receptor relationships and signaling pathways, we can develop tailored high yields of lineage specific neural cells.

Panel 4. This strategy provides promise for the treatment and repair of neurological disorders. Rat image obtained from: http://www.transposagenbio.com/hubfs/ products/tpb-Productlmage-Rat-02.png?t=1487023367000; human image obtained from: https://commons.wikimedia.org/wiki/File:Human_body_silhouette.svg.

\section{KEY CONCEPTS}

1. Stem cells are unspecialized cells capable of self-renewal and differentiation into specialized cell types under appropriate conditions.

2. Neurogenesis is defined as the generation of functional neurons from neural precursors and is the first step in neural development, followed by axon guidance and synaptogenesis.

3. Neural stem cells, embryonic stem cells, induced pluripotent stem cells, and mesenchymal stem cells are all capable of differentiating into neural cell types. 
4. Neurological disorders, including traumatic brain injuries and neurodegenerative diseases are commonly characterized by the loss of neural cells-current treatments provide some symptomatic improvement thus stem cell therapy in the form of cell/tissue replacement is a promising alternative.

5. Heparan sulfate proteoglycans (HSPGs) are ubiquitous molecules on the cell surface and in the extracellular matrix which act as intermediaries between the extracellular matrix and intracellular signaling pathways, playing critical roles in numerous cellular activities.

6. Syndecans, glypicans, and perlecan HSPGs carry heparan sulfate (HS) chains as a constant feature. They are expressed sequentially throughout mammalian neural development as progenitor cells progress through lineage differentiation.

7. Emerging biomimetic strategies are designed to mimic the interactions between HSPGs and key growth factors of neural lineage specification. These molecules may enable greater efficacy than natural HS GAGs in promoting neural differentiation, and are promising approaches for improving and advancing stem cell therapies for the treatment of neurological disorders.

\section{INTRODUCTION}

Stem cells have the ability to self-renew through cell division and the capability to generate specialized cell types through differentiation under appropriate conditions (Fossett and Khan, 2012). Autologous (patient) or allogeneic (donor) transplantation of stem cells to regenerate tissue and repair damaged organs provide an exciting avenue for regenerative medicine. Neurological disorders encompass injuries or diseases of the nervous system, including neurodegenerative diseases and traumatic brain injuries. Effective regeneration of brain tissue requires damaged cells be replenished as well as their integration with existing cells to form new functional neural networks (van Velthoven et al., 2009). Injuries of the central nervous system (CNS) present therapeutic challenges as current treatments are unable to achieve complete functional recovery, even with symptomatic improvements (Neirinckx et al., 2013; Srijaya et al., 2014). To circumvent these limitations, a better understanding of the factors that control stem cell neural lineage specification is needed. In this review, we examine mechanisms within the neural niche influencing stem cell neural lineage potential, with a focus on the extracellular matrix heparan sulfate proteoglycans, and their role in stem cell neural fate determination.

\section{STEM CELL NEUROGENESIS}

Neurogenesis is defined as the generation of functional neurons from neural precursors and is the first step in neuronal development, followed by axonal and dendritic guidance and synaptogenesis (Gage et al., 1998; Yamaguchi, 2001). Post-natal neurogenesis occurs throughout life in two selective neurogenic regions in the brain: the subventricular zone (SVZ) within the lateral ventricles, where resulting neurons migrate to the olfactory bulb (OB) through the rostral migratory system (RMS); and in the subgranular zone (SGZ) within the dentate gyrus of the hippocampus, where neurons ultimately migrate to the granular cell layer (GCL) to complete maturation (Zhao et al., 2008; Ming and Song, 2011; Gonçalves et al., 2016).

NSCs pass through a series of tightly regulated developmental stages governed by genetic, epigenetic and environmental signals before fully maturing to neurons (Urbán and Guillemot, 2014). During this process NSCs adopt specific marker expression profiles that have contributed to our ability to resolve the various stages of neuronal differentiation. These phenotypic markers are not sequential in their expression; rather they are transient overlapping markers expressed throughout lineage commitment (Kuhn et al., 2016). Although, these phenotypic markers provide a pattern with which to monitor neural development, their associated underlying molecular signaling events are currently not well understood.

In the event of insult to the brain, neurogenesis is triggered, resulting in production of neuroblasts that migrate from neurogenic niches to the site of injury. However, the inflammatory microenvironment present at the injury site is hostile to neuroblast survival, limiting the capacity of the brain for self-regeneration and repair (Galindo et al., 2011). In the case of neurodegeneration, the rate of cell loss exceeds that of generation of new neurons (Venugopal et al., 2017). With the balance of damage to regeneration unable to be met by the brain, obtaining neural cells from exogenous sources able to augment or direct repair is an important potential therapeutic tool (Neirinckx et al., 2013).

\section{NEURAL CELL SOURCES FOR THERAPEUTIC APPLICATIONS}

Stem cell therapy is an emerging and promising approach for treatment of various neurological disorders through the transplantation of autologous or allogeneic stem cells via systemic infusion or local delivery (Law and Chaudhuri, 2013; Hao et al., 2014). Several stem cell-based therapeutic strategies may be applied to treating neurological disorders with stem cells able to enrich the NSC niche (enhance neurogenesis of endogenous NSCs) via the release of neuroprotective factors as well as becoming self-renewing neural progenitors (Sadan et al., 2009). With neurogenesis by NSCs following insult to the brain insufficient, obtaining neural cells from other sources is required. However, current models lack efficacy in the direction and control of stem cell neurogenesis to generate functioning neurons in adequate numbers for treatments (Sadan et al., 2009; Ma, 2010). Several studies examining transplanted stem cell migration to damaged areas have identified some success in terms of neuron function. This includes the use of murine NSC and MSCs in various traumatic brain injury and neurodegenerative disease models (Studer et al., 1998; Riess et al., 2002; Wang S. P. et al., 2012) as well as human NSCs (hNSCs) in murine stroke models (Jeong et al., 2003; Chu et al., 2004; Lee et al., 2007), supporting stem cell therapies in the treatment of neurological disorders (Kim and de Vellis, 2009; Assinck et al., 2017). In 
addition, neural progenitors and mature neural cells have been successfully generated from ESCs, iPSCs, NSCs, and MSCs (Kim and de Vellis, 2009).

\section{Neural Stem Cells (NSCs)}

NSCs are isolated from the neurogenic regions of the adult brain (SVZ, SGZ), and from multiple regions of the embryonic brain. NSCs can be propagated in vitro as neurospheres or adherent cultures in serum-free media under high concentration of mitogens, such as fibroblast growth factor (FGF) and epidermal growth factor (EGF) (Gage, 2000). In culture, FGF-2 promotes NSC self-renewal and regulates neural progeny fate, with higher FGF-2 concentrations promoting the generation of glial cells and lower FGF-2 concentration producing cultures primarily of neurons (Yamaguchi, 2001). Differentiation protocols are now relatively routine through plating NSCs on extracellular matrix substances such as laminin to promote neural differentiation into neurons, astrocytes, and oligodendrocytes (Conti et al., 2005). Some consensus exists when characterizing differentiating NSCs, with the expression of the NSC marker nestin, neuronal lineage markers $\beta$ III-tubulin, MAP2, NeuN, and the astrocyte lineage marker GFAP commonly used to identify lineage potential of isolated and expanded cultures. Transplanted NSCs have been shown to survive in animal brain injury models and migrate to become region-specific cells, although only a small number of NSCs achieved this with a reported lack of neurogenesis observed (Gincberg et al., 2012; Rolfe and Sun, 2015). Challenges remain regarding the proliferation capacity of NSCs, likely due to the scarcity of hNSCs derived from surgical resections or postmortem biopsies, as well as ethical issues surrounding the use of embryo-derived NSCs (Nam et al., 2015).

\section{Embryonic Stem Cells (ESCs)}

ESCs are pluripotent cells originating from the inner cell mass of the blastocyst with high expansive potential and ability to give rise to cell lineages of all three germ layers (Zhang et al., 2001; Cai et al., 2008). ESCs are commonly induced to neural cell types in vitro through methods that recapitulate the embryonic neural development process (Abranches et al., 2009). This includes embryoid body (EB) formation in the presence of retinoic acid or conditioned media (Kurosawa, 2007); or through a monolayer culture system in the presence of FGF and notch ligands together with the bone morphogenetic protein (BMP) antagonist, noggin (Ying et al., 2003; Kunath et al., 2007). In a mouse temporal lobe epilepsy model, ESC-derived neural progenitor cells (NPCs) displayed enhanced survival and differentiation in the GCL when transplanted into the dentate gyrus (Venugopal et al., 2017). Interestingly, a study using an Alzheimer's disease mouse model has shown transplantation of undifferentiated ESCs led to extensive teratoma formation (Wang et al., 2006). This, combined with ethical and political issues surrounding the derivation of ESCs from embryonic tissue poses hurdles for their use in clinical practice (Venugopal et al., 2017).

\section{Induced Pluripotent Stem Cells (iPSCs)}

iPSCs are somatic cells reprogrammed to a pluripotent state via retroviral transduction of the same four transcription factors:
OCT3/4, SOX2, Klf4, and c-Myc (Takahashi et al., 2007). Thus, iPSCs possess potential as an autologous source for treatment as well as to alleviate ethical concerns surrounding their use as they are easily derived from adult tissues (Compagnucci et al., 2014). iPSCs, commonly reprogrammed from fibroblasts, share similarities with ESCs in morphology, proliferation, gene expression, surface antigens and epigenetic profile, and like pluripotent cells they can differentiate into neurons and glial cells (Dolmetsch and Geschwind, 2011; Liu et al., 2013). However, tumorigenesis and genetic abnormalities of iPSCs have been reported, which must be addressed before they are safe for clinical use (Hunsberger et al., 2016; Nagoshi and Okano, 2017).

\section{Mesenchymal Stem Cells (MSCs)}

MSCs are somatic stem cells commonly isolated from aspirates of the iliac crest bone marrow, although they can also be isolated from other tissues including dental pulp, umbilical cord blood, adipose tissue, trabecular bone and the placenta (DiGirolamo et al., 1999; Ma, 2010). Various groups including ours have shown MSCs to express neural genes, including nestin, glial fibrillary acidic protein (GFAP), and BIII-tubulin (TUBB3) in their undifferentiated state (Montzka et al., 2009; Foudah et al., 2013; Okolicsanyi et al., 2014, 2015). In addition, MSCs have been shown to migrate to the brain upon transplantation and differentiate into neuronal cells (Eglitis and Mezey, 1997). To date, there have been limited reports on the side effects of MSCs in clinical applications (Wagner et al., 2010), with several experimental studies reporting positive outcomes in the use of MSCs in the treatment of brain injury (reviewed elsewhere; van Velthoven et al., 2009). However, the number of transplanted stem cells to date has been small when compared with lesion injury volume and the portion of transplanted stem cells differentiating into neurons insufficient to adequately replace the damaged neural tissue (van Velthoven et al., 2009).

\section{THE STEM CELL NICHE}

The stem cell niche is described as the microenvironment that encompasses all the elements immediately surrounding stem cells when they are in their naïve state (Chen, 2010). The ECM, a major constituent of the stem cell niche, is a complex threedimensional macromolecular structure directing spatiotemporal cues that influence stem cell behavior. Cellular components within the ECM contribute to its structure and remodeling reflecting its tissue specificity primarily through interactions with the cell surface, an active area where surface receptors interact with the ECM to modulate cellular processes (KirnSafran et al., 2009). Stem cells residing in the ECM influence cell signaling through secretion of ECM components, and these cells also receive and respond to critical biochemical and physical cues from the ECM (Chen, 2010). Traditionally the ECM was thought to provide structural support and strength to cells; however, increasing evidence demonstrates that the ECM has numerous active roles during development, morphogenesis and organogenesis, including facilitating cell adhesion, proliferation, migration, specification, differentiation, and survival (Tsang et al., 2010; Gattazzo et al., 2014). In addition, a variety of 
extrinsic factors in the neural ECM control stem cell selfrenewal and differentiation, including transcription factors, growth factors, cytokines, epigenetic regulators, and non-coding RNAs (Mikami and Kitagawa, 2016). The dynamic and symbiotic relationship between the cell and ECM governs cell behavior. In order to overcome the challenges associated with the use of stem cells in neurological repair, identifying and harnessing the regulatory mechanisms underlying stem cell neural lineage differentiation is crucial.

Proteoglycans (PGs), a major constituent of the ECM, are comprised of a core protein to which several GAG chains covalently attach at specific sites (Esko et al., 2009). PGs are grouped by the GAG chains they carry and include the HSPGs, chondroitin sulfate proteoglycans (CSPGs), as well as the small leucine-rich-repeat proteins (SLRPs), all expressed in the CNS (Bulow and Hobert, 2006). PGs are centrally involved in several biological processes, including cellular growth, adhesion, migration, receptor binding, morphogen gradient formation, barrier formation, and interaction with other ECM components (Jones et al., 2002). These important proteins act as intermediaries, particularly those membrane-bound, and are often strategically located to receive environmental cues to directly influence intracellular signaling pathways. In stem cell differentiation, heparan sulfate (HS) GAGs appear to be more influential than chondroitin sulfate (CS) GAGs, potentially due to the presence of glucosamine residues in the HS sugar backbone. Pickford et al. demonstrated HS, and its highly sulfated analog heparin, to be more potent than CS in promoting neural phenotypes in mouse ESCs, likely due to chain length and structure (Pickford et al., 2011).

\section{HEPARAN SULFATE (HS)}

\section{HS Biosynthesis and Modification}

The production of HS is not encoded by a single gene, but rather occurs during an elaborate posttranslational biosynthesis in the Golgi apparatus upon arrival of the core protein from the endoplasmic reticulum (Helledie et al., 2012). This process is initiated by the addition of an amino acid to a Glucuronic Acid-Galactose-Galactose-Xylose tetrasaccharide linker attached to the core protein via $O$-glycosylation of a serine residue. The tetrasaccharide linker is found on both HS and CS chains thus the attachment of the first $\mathrm{N}$-acetylglucosamine (GlcNAc) residue is the commitment step of HS biosynthesis, a process catalyzed by exostosin-like 3 (Extl3) (Lindahl et al., 1998; Bernfield et al., 1999; Sarrazin et al., 2011). The enzyme complex composed of exostosin (EXT) family of enzymes, EXT1 and EXT2, performs HS chain polymerization through addition of alternating glucuronic acid (GlcA) and GlcNAc residues to the growing chain (Haupt et al., 2009; Sarrazin et al., 2011). The final HS chain length can vary over 10 -fold dependent on cell type and the core protein, becoming 50-150 disaccharides in length once assembled (Bernfield et al., 1999).

After chain synthesis, successive modifications occur, beginning with replacement of $\mathrm{N}$-acetyl groups of GlcNAc units with a sulfate group catalyzed by the $N$-deacetylase $/ N$ sulfotransferase (NDST) family of enzymes. This is a partial process as NDSTs modify GlcNAc in clusters, leaving modified regions (N-sulfated, NS domains) interposed between unmodified regions (N-acetylated, NA domains) (Lindahl et al., 1998; Bernfield et al., 1999). NDSTs are responsible for the overall design of the HS chain as all subsequent modifications rely on the presence of the $\mathrm{N}$-sulfoglucoamine residues (Grobe and Esko, 2002; Sugahara and Kitagawa, 2002). The next modification is C-5 epimerization of a GlcA immediately adjacent to an $\mathrm{N}$-sulfoglucosamine unit to iduronic acid (IdoA), by C5 epimerase (C5-EP) (Sarrazin et al., 2011). A series of $\mathrm{O}$-sulfation modifications then occur, beginning with iduronosyl 2-O-sulfotranferase (HS2ST), then glucosaminyl 6-O sulfotransferases (HS6ST) followed by glucosaminyl 3-O sulfotransferases (HS3ST), concluding the modification process in the Golgi apparatus (Bernfield et al., 1999; Sugahara and Kitagawa, 2002). Upon arrival at the cell surface or ECM, additional modifications may occur through 6-O-endo-sulfatases (Sulf1/2) and/or by the endoglycosidase heparanase (HPSE), further enhancing the heterogeneity and complexity of HSPGs (Sarrazin et al., 2011). It is through this structural diversity that these proteins selectively interact with a wide range of proteins, including FGFs, BMPs, and Wnts, and contribute to the regulation of stem cell behavior (Pulsipher et al., 2015).

\section{HS and Neural Development}

HS is essential for mammalian brain development. This influence is generally accepted to occur through specific sulfation patterns, which serve as recognition elements for growth factors and other signaling molecules. As such, the biosynthesis and modification enzymes of HS are central to the final HS structure and its influence (Inatani et al., 2003; Gama et al., 2006). Expression of HS biosynthetic enzymes, including different isoforms, occur through spatiotemporal interactions. As a result, the HS profile of stem cells as they progress through various stages of differentiation are constantly undergoing modification (Kraushaar et al., 2013). Predictably, depletion of EXT1, NDST1/2, and selected HS2ST, HS6ST and Sulf isoforms have been demonstrated to result in brain abnormalities and malfunction in mouse models (Grobe and Esko, 2002; Inatani et al., 2003; McLaughlin et al., 2003; Pratt et al., 2006; Kalus et al., 2009). In general, when stem cells begin to differentiate the overall HS content within the microenvironment along with the processes regulating sulfation are active, indicated by increased expression of HS biosynthesis and modification enzymes (Forsberg et al., 2012; Tamm et al., 2012; Wang et al., 2017). In mouse ESCs (mESCs), 80\% of the GAGs produced are HS when cells are in their undifferentiated state, with only $\sim 30 \%$ N-sulfated (Smith et al., 2011; Kraushaar et al., 2013). Some increase in $\mathrm{N}-, 3-\mathrm{O}$-, and 6-O-, and 2-O-sulfation is observed when mESCs transition into neural lineages reflective of the conversion of neuroepithelial cells from a proliferative to neuronal differentiative state (Johnson et al., 2007).

Neurogenesis is regulated by a number of growth factors, with the association between HS and FGFs one of the most characterized interactions. FGF2 is known to promote NSC, MSC, and pluripotent stem cell proliferation (Dombrowski et al., 2009); and promotes phosphorylation of serine/threonine kinase 
(Akt) and MAP kinases, extracellular signal-regulated kinases (Erk1/2) and c-Jun N-terminal kinase (JNK), to control cell proliferation and survival (Yamada et al., 2017). For effective FGF signaling, FGF2 must bind to its high affinity FGF receptor (FGFR) with the lower affinity HS present (Yayon et al., 1991), forming the FGF-FGFR-HS complex in a 2:2:2 ratio in combination with FGFR dimerization (Gasimli et al., 2012). The presence of 2-O-sulfation in particular permits the binding of FGF2 to HS and subsequent Erk1/2 activation, with 6-O-sulfation required for inducing FGF2 activity via FGFR (Sugaya et al., 2008; Chan et al., 2015). A study by Stavridis et al. demonstrated for mESC neural specification to take place, FGF-induced Erk signaling is required for a discrete period of time, without this interaction, differentiation halts (Stavridis et al., 2007).

As cells switch from a proliferative state to lineage differentiation, increased 6-O-sulfation is accompanied by changes in FGF signaling and from a requirement of FGF2 to one for FGF1 (Brickman et al., 1998). The presence of 6-O-sulfation sites is regulated by isoforms of HS6ST and Sulf $1 / 2$, subsequently regulating the interaction between HS and a number of heparin-binding growth factors. Overexpression of the Sulfs results in reduced 6-O-sulfation and as demonstrated by Kalus et al. (2015); with Sulf knockout mice exhibiting brain development deficiencies, including reduced cell migration, survival and neurite outgrowth due to disruption of FGF2 and glial cell line-derived neurotrophic factor (GDNF) signaling (Kalus et al., 2009, 2015; Yamada et al., 2017). FGF4 is required during neural differentiation and is reduced in NDST1/2 double knockout mice, indicating FGF4 requires $\mathrm{N}$-sulfation for signaling (Johnson et al., 2007). Wnt signaling, a crucial pathway in neural development, binds HS to exert its activity and is regulated by Sulf remodeling and 6-O-sulfation (Ai et al., 2003). During the later events of neuronal differentiation, HS has been demonstrated to play an essential role in synaptogenesis and neuronal excitability. Notably, removal of highly sulfated HS moieties by heparinase treatment leads to epileptiform bursts with long periods of inactivity due to impairment of long-term potentiation during synaptic transmissions (Korotchenko et al., 2014; Minge et al., 2017).

Contrary to the neuronal lineage, in the oligodendrocyte lineage, oligodendrocyte precursor cells (OPCs) carry HS chains with more 2-O- and 6-O-sulfation than mature oligodendrocytes, accompanied by higher transcript levels of HS2ST, NDST3, and C5-EP. FGF2 is the key growth factor in regulating OPC proliferation and maintenance, interacting with 2-O- and 6-Osulfation sites (Properzi et al., 2008). HS sulfation alters as OPCs differentiate, with reduced $\mathrm{N}$ - and 6-O-sulfation biosynthesis accompanied by a reduced affinity for FGF2 (Stringer et al., 1999). Interestingly, we have demonstrated culture of embryo-derived hNSCs in astrocyte differentiation culture conditions results in up-regulation of NDST3 and HS6ST1, indicating an increased requirement for 6-O-sulfation in the astrocyte lineage, similar to observations in neuronal differentiation (Oikari et al., 2016b).

In addition, our group recently published evidence of HSPGs as novel markers of hNSC fate determination, one of only a few studies examining HSPGs in human cell models (Oikari et al., 2016b). In particular, when we examined HSPG biosynthetic machinery markers during neuronal differentiation of hNSCs, we observed up-regulation of EXT2, NDST2, NDST4, HS6ST2, and HS6ST3, suggesting an increasing reliance on 6-O sulfation, similar to EB formation from ESCs (Nairn et al., 2007). Interestingly, when we compared hNSCs with the more cortexderived lineage-restricted normal human neural progenitor cells (nhNPCs), the nhNPCs were shown to expresses higher levels of C5-EP, NDST2, NDST4, HS6ST1-3, and HPSE but lower levels of EXT2 and HS2ST1. This suggests existing chains within the cellular microenvironment are modified from 2-O to 6-O-sulfation to accommodate the change in growth factor requirement (Oikari et al., 2016a).

\section{HSPGS AND NEUROGENESIS}

HSPGs are comprised of a core protein with one or more HS side chains attached. HSPGs can be classed based on their cellular localization, with syndecans (SDCs) and glypicans (GPCs) membrane-bound; perlecan, agrin, and type XVIII collagen secreted into the ECM; and serglycin localized to secretory vesicles (Bernfield et al., 1999). SDCs, GPCs, and perlecan carry HS as a constant feature, with other HS carrying proteoglycans often decorated with other GAGs (Kraushaar et al., 2013). As most of our current understanding of HSPGs in neural development are derived from studies in rodents, distinct physiological and structure differences between human and rodent brains (reviewed in Oikari et al., 2014) suggest further studies of human neurogenesis is essential to advancing human neural stem cell therapies. Here we focus on the role of the SDCs, GPCs, and perlecan HSPGs in the context of neural lineage progression in vivo and in vitro.

\section{Membrane-Bound HSPGs}

SDCs are a family of type I transmembrane core proteins of the cell surface capable of carrying HS and CS chains, which are $O$-linked to a serine or threonine residue at the core protein (Xian et al., 2010). Four SDC genes exist in vertebrates (SDC14) and they all consist of an extracellular domain (ectodomain) at the $\mathrm{N}$-terminal end, a hydrophobic transmembrane domain (TM), and a short cytoplasmic domain at the C-terminal (Lopes et al., 2006; Figure $\mathbf{1}$ inset). Through their cytoplasmic domains, the SDCs mediate transmembrane signaling of cytoskeletal and other signaling molecules. Interactions with PDZ-containing domains via their $\mathrm{C} 2$ region occurs through direct linkage to intracellular components, including the cytoskeleton and internal scaffolding (Rapraeger and Ott, 1998; Hsueh and Sheng, 1999). The ectodomain is specific for each SDC and contains several consensus sequences for GAG attachment (Carey, 1997).

During neural development, SDC1 has been shown to be highly expressed in the SVZ by neural precursor cells (NPCs) (including NSCs and radial glia cells) where it regulates proliferation and maintenance of NPCs (Figure 1, stem cell state, Steps 1 and 2). Wang Q. et al. identified disrupted canonical Wnt signaling in an SDC1 knockdown murine model due to reduced $\beta$-catenin, resulting in reduced cell proliferation and premature differentiation (Wang Q. et al., 2012). Also involved in early brain development, SDC4 expression can be detected at a 


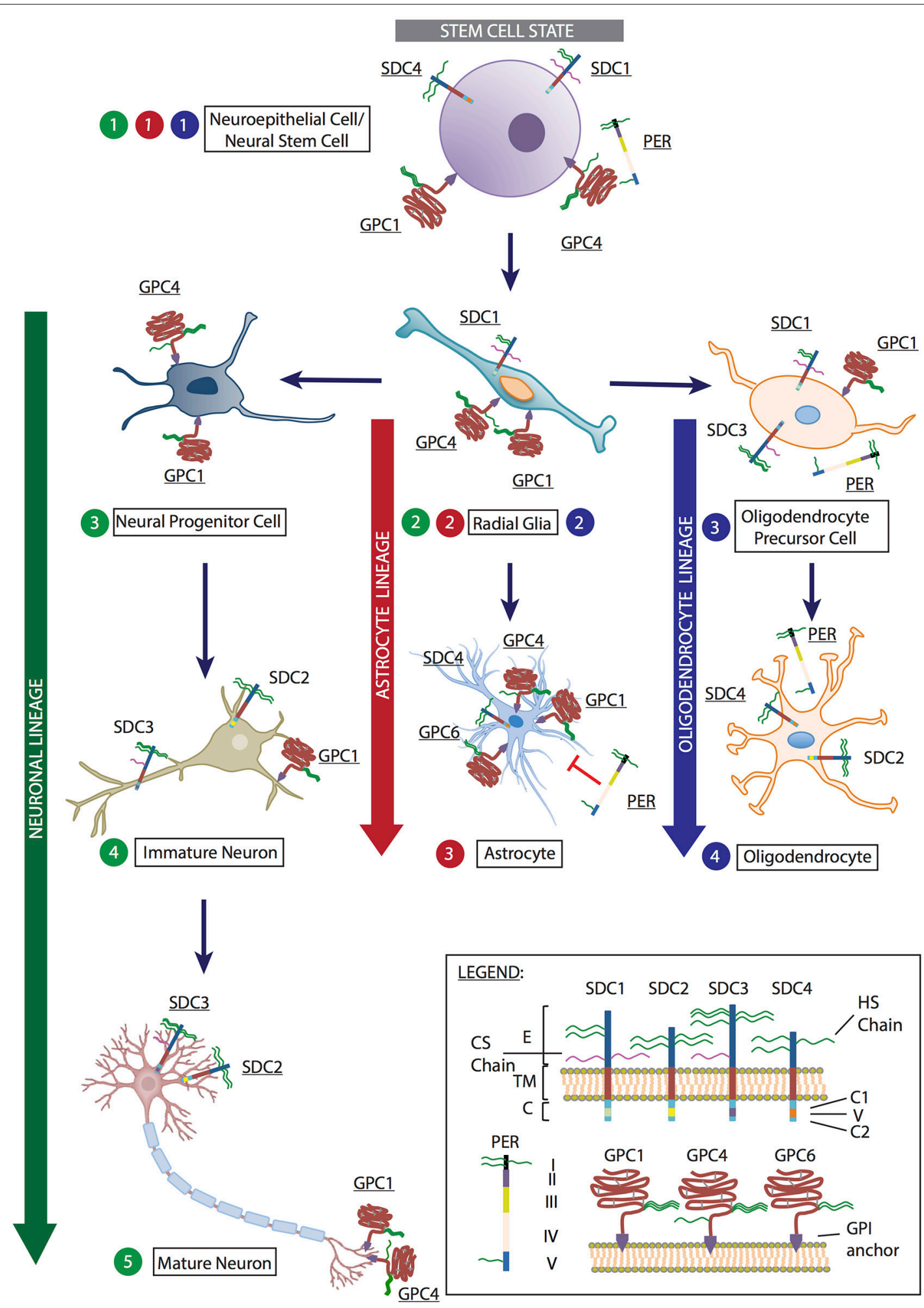

FIGURE 1 | Representation of heparan sulfate proteoglycans (HSPGs) expressed by cells at various stages of neural stem cell differentiation into neuron, astrocyte and oligodendrocyte lineages. At the stem cell state (denoted in gray), neuroepithelial cells/neural stem cell (Step 1) expresses the HSPGs syndecan-1 (SDC1), syndecan-4 (SDC4), glypican-1 (GPC1), glypican-4 (GPC4), and perlecan (PER). These HSPGs mediate cell proliferation and maintenance of the pluripotent state via FGF and Wnt signaling. As cells begin to enter differentiation programs, they become radial glia (Step 2), with the potential to differentiate into the three main neural lineages: neurons, astrocytes and oligodendrocytes. At this stage, radial glia cells express SDC1, GPC1, and GPC4. Differentiation toward the neuronal lineage 


\section{FIGURE 1 | Continued}

(denoted in green) results in the formation of neural progenitor cells (neuronal Step 3), which expresses GPC1 and GPC4. As cells progresses to immature neurons (neuronal Step 4), syndecan-2 (SDC2) is expressed on dendritic spines to promote dendritic maturation; syndecan-3 (SDC3) is localized to axons to assist axon guidance with GPC1 during synapse formation. This is also observed in mature neurons (neuronal Step 5) in conjunction with GPC4 mediation of excitatory synapse development through LRRTM4 binding. In astrocyte lineage differentiation (denoted in red), as radial glia cells differentiate toward astrocytes, SDC1 expression diminishes, SDC4 and glypican-6 (GPC6) expression becomes detectable while GPC1 and GPC4 expression is retained (astrocyte Step 3). The presence of PER is inhibitory to astrocyte proliferation due to the presence of domain V (astrocyte Step 3). In the oligodendrocyte lineage (denoted in blue), oligodendrocyte precursor cells (oligodendrocyte Step 3) derived from radial glia cells retain SDC1 and GPC1 expression, with these HSPGs assisting in cell proliferation and inhibiting differentiation. SDC3 and PER expression are up-regulated at this stage. As oligodendrocytes are formed (oligodendrocyte Step 4), SDC2 and SDC4 become the predominately expressed HSPGs, along with PER. (Inset) Legend: Syndecan-1-4 (SDC1-4). E, ectodomain; TM, transmembrane domain; C, cytoplasmic domain, including two conserved regions $\mathrm{C} 1$ and $\mathrm{C} 2$, and a variable region (V). Perlecan (PER) comprised of domains I-V. Glypican-1,-4, and-6 (GPC1, GPC4, and GPC6) are attached to the cell surface via a GPI-anchor. Astrocyte image obtained from: https://commons.wikimedia.org/wiki/File:Diagram_of_an_astrocyte_-_a_type_of_ glial_cell_CRUK_029.svg. Mature neuron image modified from: https://online.science.psu.edu/bisc004_activewd001/node/1907.

reduced level in the ventricular zone (Ford-Perriss et al., 2003). SDC3 has been identified to play an essential role in promoting neuronal migration through binding GDNF via its HS chains to transduce GDNF signaling or by presentation of GDNF to its receptor tyrosine kinase, subsequently activating $\mathrm{Src}$ kinase (Bespalov et al., 2011; Poulain and Yost, 2015). SDC3 also acts as a receptor for heparin binding growth associated molecule (HB-GAM) in neurons to induce cytoskeletal changes via its $\mathrm{C}$-terminal, thus playing a crucial role in the developing axon tract and promoting neurite outgrowth (Yamaguchi, 2001; Winkler et al., 2002; Figure 1, neuronal lineage, Steps 4 and 5). The conserved cytoplasmic domain of SDC2 contains four tyrosine residues, phosphorylated by Eph receptor tyrosine kinases to initiate dendritic spine morphogenesis (Ethell et al., 2001). Localization of SDC2 has been shown to be restricted to the synapses, where it contributes to dendritic spine formation, promoting polysialic acid-neural cell adhesion molecule-mediated synaptogenesis via its HS chains (Yamaguchi, 2001; Dityatev et al., 2004; Wang Q. et al., 2012), and accelerating synapse maturation via interaction with FGF22 (Hu et al., 2016; Figure 1, neuronal lineage, Steps 4 and 5).

Additionally, all SDCs are actively involved in the glial lineages. Oligodendrocyte progenitor cells (OPCs) expresses SDC1 and SDC3 where 2-O and 6-O-sulfated sites on the HS chains carried by SDC3 interact with FGF2 (Bansal et al., 1996; Winkler et al., 2002; Figure 1, oligodendrocyte lineage, Step 3). SDC3 also plays a role in OPC migration where it acts as a coreceptor for FGF2 and as a receptor for HB-GAM (Winkler et al., 2002). As OPCs differentiate to mature oligodendrocytes, SDC2 and SDC4 are the predominantly expressed SDCs (Bansal et al., 1996; Properzi et al., 2008; Figure 1, oligodendrocyte lineage, Step 4). SDC4 is the only SDC reported to be expressed in rat astrocytes (Avalos et al., 2009; Figure 1, astrocyte lineage, Step 3).

GPCs are a family of HSPGs attached to the exocytoplasmic surface of the plasma membrane via a glycosylphosphatidylinositol (GPI) anchor (Feng et al., 2012). Six GPC family members can be found in mammalian cells (GPC1-6) comprised of the characteristic pattern of 14 highly conserved cysteine residues, located near the $\mathrm{N}$-terminus or central domain of the core protein (Fransson, 2003). These residues are thought to form intramolecular disulfide bonds, giving GPCs a conserved globular tertiary structure (Song and Filmus, 2002; Fico et al., 2011; Figure 1 inset).
GPC4 is most predominantly expressed during mouse neural development in the ventricular zone of the telencephalon, and acts as a modulator of FGF2 to maintain NSC and NPC proliferation and self-renewal (Hagihara et al., 2000; Yamaguchi, 2001; Ford-Perriss et al., 2003). GPC4 appears to be a marker of stem and progenitor cells (Figure 1, stem cell state, Steps 1 and 2; neuronal lineage, Step 3), with its expression lost as cells commit to neural lineage differentiation and maturation (Figure 1, neuronal lineage, Steps 4 and 5), as observed in rodents in vivo, NSCs in vitro (Hagihara et al., 2000; Ford-Perriss et al., 2003; Gasimli et al., 2012), and mouse ESCs (Fico et al., 2012). Interestingly, various group have shown leucine-rich repeat transmembrane proteins (LRRTM) to be important regulators of excitatory synaptogenesis in vivo and in cultured rodent dentate granule neurons. HSPGs, particularly GPC4, were found to be novel presynaptic receptors of LRRTM, binding preferentially to postsynaptic LRRTM4 and not LRRTM2 via HS chains (de Wit et al., 2013; Siddiqui et al., 2013; Figure 1, neuronal lineage, Step 5). Additionally, protein tyrosine phosphatase sigma (PTP $\sigma)$ is a presynaptic receptor for the GPC4/LRRTM4 complex, with the HS-binding ability of PTP $\sigma$ essential for excitatory synapse transmission (Ko et al., 2015). Jen et al. demonstrated a significant reduction in brain size in GPC1-null mice, attributed to FGF17 signaling and reduced cell proliferation (Jen et al., 2009) with GPC4 and GPC1 appearing to share overlapping functions in regulating cell proliferation and brain size. Interestingly, SDC1, which also regulates neural stem and progenitor cell (NSPC) proliferation, functions through the Wnt pathway with SDC1 knock down models showing no interference with FGF signaling (Poulain and Yost, 2015; illustrated in Figure 2); with GPC1 expression observed in mature neurons localized to the axons and nerve terminals (Litwack et al., 1998; Yamaguchi, 2001; Jen et al., 2009; Figure 1, neuronal lineage). These examples demonstrate the diversity and complexity of HSPGs in regulating multiple signaling pathways to coordinate neural development. Our findings in hNSCs are comparable to the mouse model where GPC1 knockdown reduced the expression of the NSC marker nestin, and neuronal markers TUBB3 and NEFM, further supporting a key role for GPC1 in NSC proliferation and neuronal differentiation (Oikari et al., 2016b). GPC5 and GPC2 have also been identified to be expressed in post-mitotic neurons, and in axon tracts respectively (Litwack et al., 1998; Yamaguchi, 2001). 


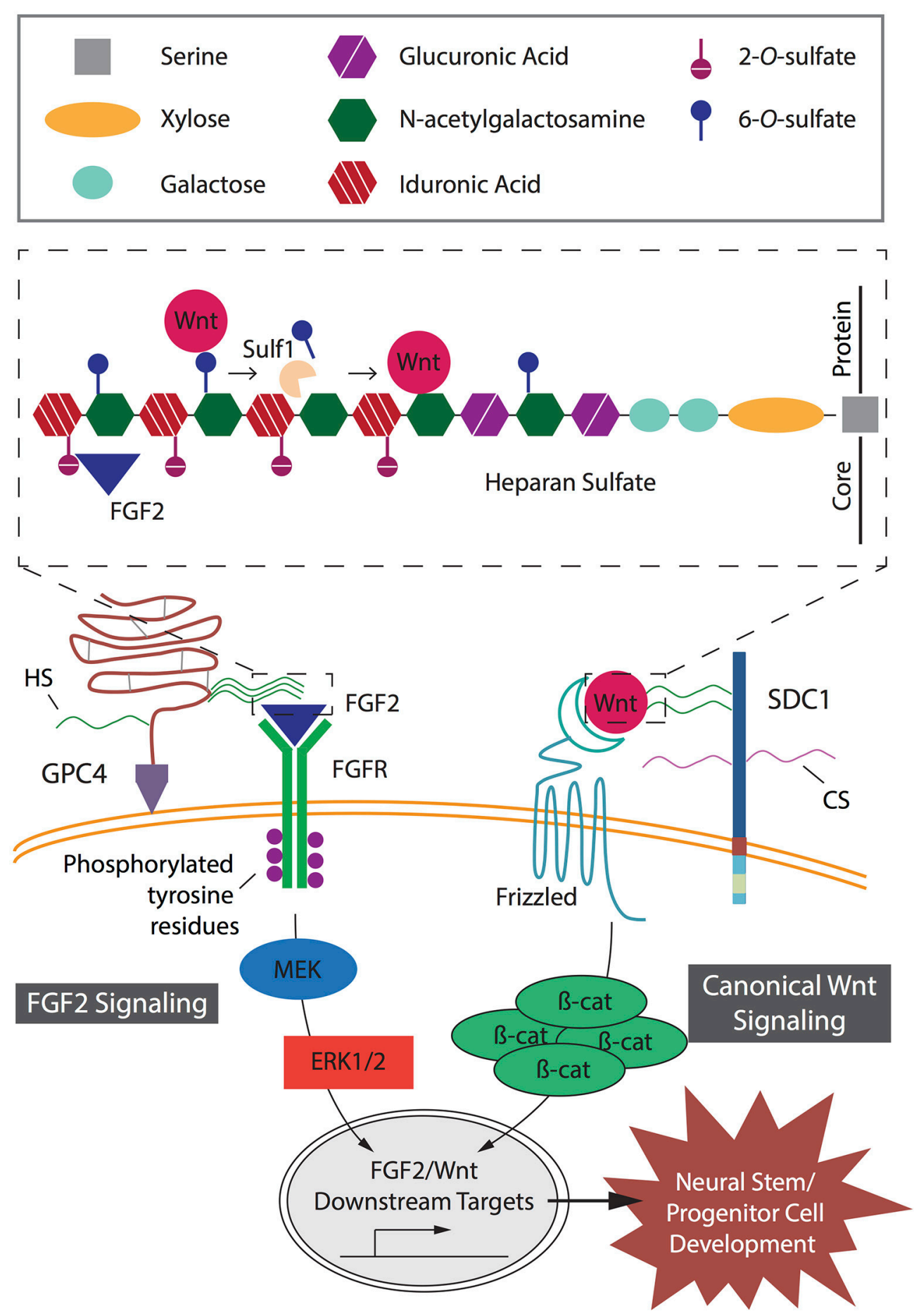

FIGURE 2 | Key heparan sulfate proteoglycan (HSPG)-mediated signaling pathways in neural stem and progenitor cell (NSPC) development. Fibroblast growth factor (FGF2) and canonical Wnt signaling pathways act independently to mediate proliferation and lineage differentiation of cells with specific interactions determined by specific heparan sulfate chain sulfation profiles. In FGF2 signaling, GPI-anchored HSPG glypican-4 (GPC4) HS chains modulate the binding of FGF2 to its receptor, FGFR. Binding of FGF2 to HS requires 2-O-sulfates (inset). Subsequent phosphorylation of tyrosine residues mediates interactions with cytosolic adaptor proteins; resulting in activation of the MEK/ERK cascade and downstream targets, key transcriptional factors promoting NSPC development. In canonical Wnt signaling, the Wht ligand binds to its receptor, Frizzled, and is mediated by SDC1 via 6-O-sulfation sites on the HS chains (inset). The presence of HS chain 6-O-sulfation sites enables high affinity binding of Wnt ligands and prevents interaction between Wnts and their Frizzled receptors. In the presence of Sulf1, selective 6-O-sulfates are removed from the HS chain, resulting in low affinity binding of Wnt ligands to the 6-O-desulfated site allowing presentation to the Frizzled receptors. Wnt binding to its receptor leads to accumulation of $\beta$-catenin in the cytoplasm, which translocates into the nucleus to activate downstream targets and promote NSPC development. 
During gliogenesis, both OPCs and oligodendrocytes express GPC1 (Figure 1, oligodendrocyte lineage), likely due to its interaction with FGF2, a crucial mitogen for OPCs to stimulate proliferation and inhibit differentiation. As OPCs differentiate, the HS chains of GPC1 are modified to alter their FGF2 binding capability (Winkler et al., 2002). Astrocytes in the developing rat CNS express GPC1, GPC4, and GPC6 (Winkler et al., 2002; Allen et al., 2012; Figure 1, astrocyte lineage). Similarly, when we examined hNSCs in astrocyte lineage culture conditions, we also observe an up-regulation of GPC4 localized to specific regions when examined by immunocytochemistry. Interestingly, siRNA knockdown of GPC4 in hNSC cultures results in downregulation of the astrocyte marker $\mathrm{S} 100 \mathrm{~B}$, supporting a role for GPC4 in mediating the astrocyte lineage (Oikari et al., 2016b).

Our work in hNSCs has also demonstrated that as the cells differentiate toward the neuronal lineage, SDC4, GPC1, GPC2, GPC3, and GPC6 are all up-regulated. Interestingly, expression of these genes was observed to be lower than the level observed in the more neuronal lineage-restricted nhNPCs, where higher gene expression levels of SDC2, 3, 4 as well as GPC1, 2, 3, and 6 were observed, similar to murine studies (Oikari et al., 2016a,b). As cell surface-bound HSPGs, SDCs, and GPCs play an important role in promoting neurogenesis and may provide additional markers for defining markers of neural cell types during lineage specification.

\section{Matrix-Localized HSPGS}

During mammalian neural development, the HSPG perlecan is expressed in the basal lamina of the neuroepithelium, a crucial component of the neural niche (Ford-Perriss et al., 2003; Figure 1, stem cell state, Step 1). Perlecan is a multi-domain HSPG of the ECM with diverse roles during development and organogenesis (Knox and Whitelock, 2006). A large protein with five domains, perlecan carries 3-4 HS chains in domain I and one in domain V (Figure 1 inset), which interact with heparinbinding growth factors such as FGF-2, EGF, and VEGF (FarachCarson and Carson, 2007). Perlecan is another multifunctional protein in the developing mouse brain, where it promotes NSPC proliferation in the SVZ by acting as a co-receptor for FGF2 (Nurcombe et al., 1993; Yamaguchi, 2001; Girós et al., 2007). FGF2 is essential in the mouse NSC niche, and requires perlecan to promote proliferation through activation of the Akt and Erk1/2 pathway, elegantly demonstrated by Kerever et al. (2014) in a perlecan null murine model. In the same study, FGF2 failed to promote neurosphere formation of $\mathrm{GFAP}^{+} \mathrm{CD} 133^{+} \mathrm{NSCs}$ owing to the inability to induce cell cycle progression via cyclin D2 (Kerever et al., 2014). In another study by Girós et al. (2007), perlecan-null mice displayed impaired forebrain development, through disrupted sonic hedgehog (Shh) signaling, with perlecan essential to mediate the Shh concentration gradient (Girós et al., 2007; Palma et al., 2011).

In vitro studies by Nakamura et al. (2015) demonstrated addition of exogenous perlecan to neural cultures promoted NSPC proliferation as well as neurite extension. Addition of heparin was found to promote NSPC proliferation, although this was not significant, suggesting perlecan as well as its associated GAGs are required. Perlecan has also been demonstrated to play a role in gliogenesis, where OPCs show increasing expression of perlecan during terminal differentiation of mature oligodendrocytes (Winkler et al., 2002; Figure 1, oligodendrocyte lineage). In contrast, perlecan expression in astrocytes has been shown to inhibit proliferation due to domain V (Figure 1, astrocyte lineage, Step 3), with heparin also shown to a lesser extent to suppress astrocyte proliferation (Nakamura et al., 2015). With its contribution to differentiation of the astrocyte and oligodendrocyte lineages, perlecan is likely a marker for glial lineage specification.

\section{APPROACHES FOR EXPLOITING HSPGS AS THERAPEUTIC TARGETS}

The emerging evidence of a central role for HSPGs in regulating neural stem cell lineage fate may provide opportunities to better understand and control lineage specification and to fully exploit the use of stem cells as effective therapeutics. With HSPGs involved at all stages of stem cell maintenance and neurogenesis, including proliferation, self-renewal, differentiation, migration, and maturation, multiple opportunities exist to develop improved therapeutics.

Stem cell fate can be directed through exogenous and synthetic HSPGs and GAGs. Exogenous heparin, the highly sulfated analog of HS, is a widely utilized means of enhancing HS-mediated stem cell proliferation and self-renewal (Figure 3; Fossett and Khan, 2012). The study performed by Pickford et al. (2011), identified the heparin effect is dependent on size (length) and concentration (Pickford et al., 2011), and varies between cell culture systems with sensitivity to heparin observed to differ between hMSC and hESC cultures (Mimura et al., 2011). In order to enhance the effect of heparin, a popular strategy is to conjugate heparin with assorted biomaterials (Figure 3; van Velthoven et al., 2009 and reviewed in Sakiyama-Elbert, 2014). The Sakiyama-Elbert group (2014) devised an affinitybased delivery system through the combination of a biomaterial, heparin and growth factors. They suggest this conjugation enhances the capability of heparin to bind a wide range of growth factors, preventing degradation and potentiating receptor binding via a controlled release mechanism (Willerth et al., 2008).

Harnessing HSPG and growth factor interactions has also resulted in various forms of HS mimetics and synthetic glycopolymers that mimic natural occurring HSPGs and their function during stem cell neural differentiation. These strategies have produced synthetic glycopolymers with even higher efficacy than heparin (Figure 3; Neirinckx et al., 2013). In other studies, Liu et al. (2017) devised a phospholipid-anchored GAGmimicking polymer, termed "lipo-pSGF," found to promote neural differentiation, likely via the FGF2-Erk1/2 pathway, in mESC cultures and have compared its efficacy to non-anchored pSGF and heparin treated cultures. The lipid-anchor maintained the lipo-pSGF on the cell surface without being exocytosed (Liu et al., 2017). In another variation, Huang et al. (2014) generated 


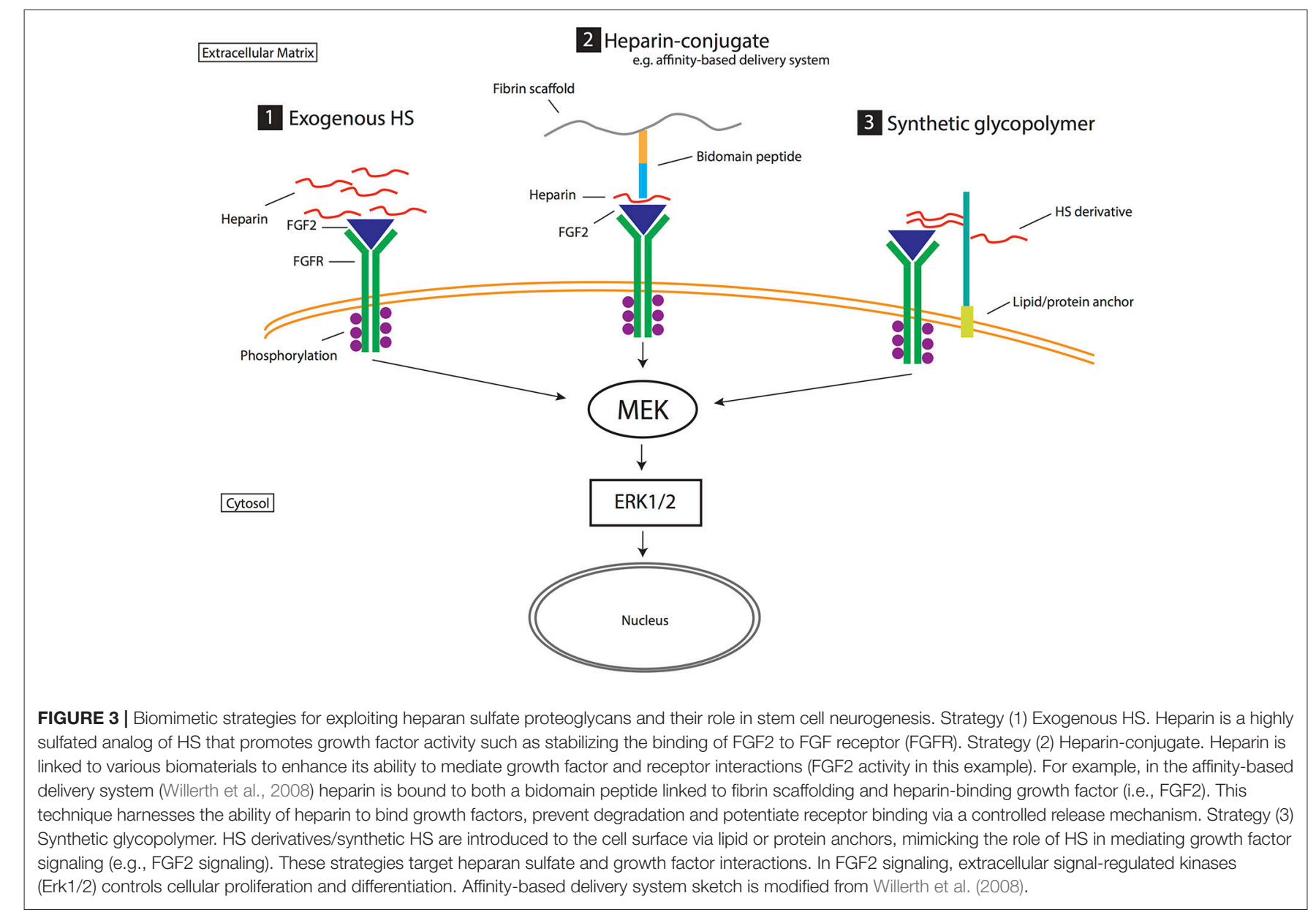

synthetic neoproteoglycans (neoPGs) that also promoted neural differentiation of mESCs via the FGF2/Erk pathway (Huang et al., 2014). Similarly, Pulsipher et al. covalently attached GAG derivatives to the cell membrane of mESCs via a HaloTag protein (HTP) anchor, which provided a longer (more than a week), stable presentation of defined HS GAGs when compared to lipid-anchoring (Pulsipher et al., 2015). Through both the HTP anchor and defined sulfation pattern on the HS derivative, the FGF/Erk pathway was activated to promote enhanced exit of mESCs from self-renewal to differentiation of neuronal cell types (Figure 3). Despite these promising data, there is no current compound that fully mimics natural HSPGs (Pulsipher et al., 2015). However, synthetic GAGs have some advantages over natural GAGs, and provide the opportunity to synthesize compounds of structural homogeneity, purity, and controlled sulfation to circumvent any limitations (Wang et al., 2015, 2017).

\section{CONCLUSION AND PERSPECTIVE}

Despite no current long-term/permanent therapies, stem cells have potential in cell/tissue replacement therapies for neurological disorders. Successful therapies require regimens for differentiating stem cells into desired lineages with high efficiency and yield. Current approaches include combinations of growth factors and chemicals, which often correlate with relatively poor yield of desirable cell types, and poor therapeutic efficacy. To overcome these challenges, a comprehensive understanding of the extrinsic and intrinsic signals regulating neural stem cell fate must be defined.

Identification of specific HSPGs and HS sulfation patterns as they are expressed throughout neural lineage progression will allow for distinction between neuronal, astrocyte and oligodendrocyte lineage specification and enhance derivation of these cell types from the stem cell state. HS sulfation motifs are specific for each cell type and it is essential to characterize HS structural changes in specific stem cell models. Further research, particularly in the human biological system, is required to identify point/s of intervention during neurogenesis. HS biomimetics to mimick HSPG core proteins and/or specific HS moieties are promising strategies for enriching current stem cell therapies, with more rigorous analysis required for their routine, reproducible and safe integration into therapeutic applications. Forthcoming work examining the intrinsic mechanisms governing the influence of HSPGs in mediating neural stem cell fate will likely enable better cell isolation techniques, as well as the development of tailored production of specific neural cell types for various applications and 
treatment requirements, and promote advances in biomimetic engineering.

\section{AUTHOR CONTRIBUTIONS}

CY developed the concept and drafted the manuscript. $\mathrm{LH}$ conceived of the manuscript, supervised the structure and design of the manuscript, revised the manuscript, and approved the

\section{REFERENCES}

Abranches, E., Silva, M., Pradier, L., Schulz, H., Hummel, O., Henrique, D., et al. (2009). Neural differentiation of embryonic stem cells in vitro: a road map to neurogenesis in the embryo. PLoS ONE 4:e6286. doi: 10.1371/journal.pone.0006286

Ai, X., Do, A.-T., Lozynska, O., Kusche-Gullberg, M., Lindahl, U., and Emerson, C. P. (2003). QSulf1 remodels the 6-O sulfation states of cell surface heparan sulfate proteoglycans to promote Wnt signaling. J. Cell Biol. 162, 341-351. doi: $10.1083 /$ jcb. 200212083

Allen, N. J., Bennett, M. L., Foo, L. C., Wang, G. X., Chakraborty, C., Smith, S. J., et al. (2012). Astrocyte glypicans 4 and 6 promote formation of excitatory synapses via GluA1 AMPA receptors. Nature 486, 410-414. doi: 10.1038/nature11059

Assinck, P., Duncan, G. J., Hilton, B. J., Plemel, J. R., and Tetzlaff, W. (2017). Cell transplantation therapy for spinal cord injury. Nat. Neurosci. 20, 637-647. doi: $10.1038 / \mathrm{nn} .4541$

Avalos, A. M., Valdivia, A. D., Muñoz, N., Herrera-Molina, R., Tapia, J. C., Lavandero, S., et al. (2009). Neuronal Thy-1 induces astrocyte adhesion by engaging syndecan- 4 in a cooperative interaction with alphavbeta3 integrin that activates PKCalpha and RhoA. J. Cell Sci. 122(Pt 19), 3462-3471. doi: $10.1242 /$ jcs.034827

Bansal, R., Kumar, M., Murray, K., and Pfeiffer, S. (1996). Developmental and FGF2-mediated regulation of syndecans (1-4) and glypican in oligodendrocytes. Mol. Cell. Neurosci. 7, 276-288. doi: 10.1006/mcne.1996.0021

Bernfield, M., Götte, M., Park, P. W., Reizes, O., Fitzgerald, M. L., Lincecum, J., et al. (1999). Functions of cell surface heparan sulfate proteoglycans. Annu. Rev. Biochem. 68, 729-777. doi: 10.1146/annurev.biochem.68.1.729

Bespalov, M. M., Sidorova, Y. A., Tumova, S., Ahonen-Bishopp, A., Magalhães, A. C., Kulesskiy, E., et al. (2011). Heparan sulfate proteoglycan syndecan-3 is a novel receptor for GDNF, neurturin, and artemin. J. Cell Biol. 192, 153-169. doi: $10.1083 /$ jcb.201009136

Brickman, Y. G., Ford, M. D., Gallagher, J. T., Nurcombe, V., Bartlett, P. F., and Turnbull, J. E. (1998). Structural modification of fibroblast growth factorbinding heparan sulfate at a determinative stage of neural development. J. Biol. Chem. 273, 4350-4359. doi: 10.1074/jbc.273.8.4350

Bülow, H. E., and Hobert, O. (2006). The molecular diversity of glycosaminoglycans shapes animal development. Annu. Rev. Cell Dev. Biol. 22, 375-407. doi: 10.1146/annurev.cellbio.22.010605.093433

Cai, C., Thorne, J., and Grabel, L. (2008). Hedgehog serves as a mitogen and survival factor during embryonic stem cell neurogenesis. Stem Cells 26, 1097-1108. doi: 10.1634/stemcells.2007-0684

Carey, D. J. (1997). Syndecans: multifunctional cell-surface co-receptors. Biochem. J. 327(Pt 1), 1-16.

Chan, W. K., Howe, K., Clegg, J. M., Guimond, S. E., Price, D. J., Turnbull, J. E., et al. (2015). 2-O heparan sulfate sulfation by Hs2st is required for Erk/Mapk signalling activation at the mid-gestational mouse telencephalic midline. PLoS ONE 10:e0130147. doi: 10.1371/journal.pone.0130147

Chen, X. D. (2010). Extracellular matrix provides an optimal niche for the maintenance and propagation of mesenchymal stem cells. Birth Defects Res. C Embryo Today 90, 45-54. doi: 10.1002/bdrc.20171

Chu, K., Kim, M., Park, K. I., Jeong, S. W., Park, H. K., Jung, K. H., et al. (2004). Human neural stem cells improve sensorimotor deficits in the adult rat brain with experimental focal ischemia. Brain Res. 1016, 145-153. doi: 10.1016/j.brainres.2004.04.038 final version. LG revised the manuscript and approved the final version.

\section{ACKNOWLEDGMENTS}

CY is supported by an Australian Postgraduate Award stipend; $\mathrm{LH}$ acknowledges the support of the School of Biomedical Sciences at QUT through a Ph.D. Enabling grant.

Compagnucci, C., Nizzardo, M., Corti, S., Zanni, G., and Bertini, E. (2014). In vitro neurogenesis: development and functional implications of iPSC technology. Cell. Mol. Life Sci. 71, 1623-1639. doi: 10.1007/s00018-0131511-1

Conti, L., Pollard, S. M., Gorba, T., Reitano, E., Toselli, M., Biella, G., et al. (2005). Niche-independent symmetrical self-renewal of a mammalian tissue stem cell. PLoS Biol. 3:e283. doi: 10.1371/journal.pbio.0030283

de Wit, J., O’Sullivan, M. L., Savas, J. N., Condomitti, G., Caccese, M. C., Vennekens, K. M., et al. (2013). Unbiased discovery of glypican as a novel receptor for LRRTM4 in regulating excitatory synapse development. Neuron 79, 696-711. doi: 10.1016/j.neuron.2013.06.049

DiGirolamo, C. M., Stokes, D., Colter, D., Phinney, D. G., Class, R., and Prockop, D. J. (1999). Propagation and senescence of human marrow stromal cells in culture: a simple colony-forming assay identifies samples with the greatest potential to propagate and differentiate. Br. J. Haematol. 107, 275-281. doi: 10.1046/j.1365-2141.1999.01715.x

Dityatev, A., Dityateva, G., Sytnyk, V., Delling, M., Toni, N., Nikonenko, I., et al. (2004). Polysialylated neural cell adhesion molecule promotes remodeling and formation of hippocampal synapses. J. Neurosci. 24, 9372. doi: 10.1523/JNEUROSCI.1702-04.2004

Dolmetsch, R., and Geschwind, D. H. (2011). The human brain in a dish: the promise of iPSC-derived neurons. Cell 145, 831-834. doi: 10.1016/j.cell.2011.05.034

Dombrowski, C., Song, S. J., Chuan, P., Lim, X., Susanto, E., Sawyer, A. A., et al. (2009). Heparan sulfate mediates the proliferation and differentiation of rat mesenchymal stem cells. Stem Cells Dev. 18, 661-670. doi: $10.1089 /$ scd.2008.0157

Eglitis, M. A., and Mezey, E. (1997). Hematopoietic cells differentiate into both microglia and macroglia in the brains of adult mice. Proc. Natl. Acad. Sci. U.S.A. 94, 4080-4085. doi: 10.1073/pnas.94.8.4080

Esko, J. D., Kimata, K., and Lindahl, U. (2009). "Proteoglycans and sulfated glycosaminoglycans," in Essentials of Glycobiology, Chapter 16, 2nd Edn, eds A. Varki, R. D. Cummings, J. D. Esko, H. H. Freeze, P. Stanley, C. R. Bertozzi, G. W. Hart, and M. E. Etzler (Cold Spring Harbor, NY: Cold Spring Harbor Laboratory Press), 229-248.

Ethell, I. M., Irie, F., Kalo, M. S., Couchman, J. R., Pasquale, E. B., and Yamaguchi, Y. (2001). EphB/syndecan-2 signaling in dendritic spine morphogenesis. Neuron 31, 1001-1013. doi: 10.1016/S0896-6273(01)00440-8

Farach-Carson, M. C., and Carson, D. D. (2007). Perlecan-a multifunctional extracellular proteoglycan scaffold. Glycobiology 17, 897-905. doi: $10.1093 /$ glycob/cwm043

Feng, C., Li, J., Ruan, J., and Ding, K. (2012). MicroRNA-125a inhibits cell growth by targeting glypican-4. Glycoconj. J. 29, 503-511. doi: 10.1007/s10719-012-9387-0

Fico, A., De Chevigny, A., Egea, J., Bösl, M. R., Cremer, H., Maina, F., et al. (2012). Modulating Glypican4 suppresses tumorigenicity of embryonic stem cells while preserving self-renewal and pluripotency. Stem Cells 30, 1863-1874. doi: 10.1002/stem.1165

Fico, A., Maina, F., and Dono, R. (2011). Fine-tuning of cell signaling by glypicans. Cell. Mol. Life Sci. 68, 923-929. doi: 10.1007/s00018-0077471-6

Ford-Perriss, M., Turner, K., Guimond, S., Apedaile, A., Haubeck, H. D., Turnbull, J., et al. (2003). Localisation of specific heparan sulfate proteoglycans during the proliferative phase of brain development. Dev. Dyn. 227, 170-184. doi: $10.1002 /$ dvdy. 10298 
Forsberg, M., Holmborn, K., Kundu, S., Dagälv, A., Kjellén, L., and ForsbergNilsson, K. (2012). Undersulfation of heparan sulfate restricts differentiation potential of mouse embryonic stem cells. J. Biol. Chem. 287, 10853-10862. doi: 10.1074/jbc.M111.337030

Fossett, E., and Khan, W. S. (2012). Optimising human mesenchymal stem cell numbers for clinical application: a literature review. Stem Cells Int. 2012:465259. doi: 10.1155/2012/465259

Foudah, D., Redondo, J., Caldara, C., Carini, F., Tredici, G., and Miloso, M. (2013). Human mesenchymal stem cells express neuronal markers after osteogenic and adipogenic differentiation. Cell. Mol. Biol. Lett. 18, 163-186. doi: 10.2478/s11658-013-0083-2

Fransson, L.-A. (2003). Glypicans. Int. J. Biochem. Cell Biol. 35, 125-129. doi: 10.1016/S1357-2725(02)00095-X

Gage, F. H. (2000). Mammalian neural stem cells. Science 287, 1433-1438. doi: $10.1126 /$ science.287.5457.1433

Gage, F. H., Kempermann, G., Palmer, T. D., Peterson, D. A., and Ray, J. (1998). Multipotent progenitor cells in the adult dentate gyrus. Dev. Neurobiol. 36, 249-266. doi: 10.1002/(SICI)1097-4695(199808)36:2<249::AIDNEU11>3.0.CO;2-9

Galindo, L. T., Filippo, T. R., Semedo, P., Ariza, C. B., Moreira, C. M., Camara, N. O., et al. (2011). Mesenchymal stem cell therapy modulates the inflammatory response in experimental traumatic brain injury. Neurol. Res. Int. 2011:564089. doi: 10.1155/2011/564089

Gama, C. I., Tully, S. E., Sotogaku, N., Clark, P. M., Rawat, M., Vaidehi, N., et al. (2006). Sulfation patterns of glycosaminoglycans encode molecular recognition and activity. Nat. Chem. Biol. 2, 467-473. doi: 10.1038/nchembio810

Gasimli, L., Linhardt, R. J., and Dordick, J. S. (2012). Proteoglycans in stem cells. Biotechnol. Appl. Biochem. 59, 65-76. doi: 10.1002/bab.1002

Gattazzo, F., Urciuolo, A., and Bonaldo, P. (2014). Extracellular matrix: a dynamic microenvironment for stem cell niche. Biochim. Biophys. Acta 1840, 2506-2519. doi: 10.1016/j.bbagen.2014.01.010

Gincberg, G., Arien-Zakay, H., Lazarovici, P., and Lelkes, P. I. (2012). Neural stem cells: therapeutic potential for neurodegenerative diseases. Br. Med. Bull. 104, 7. doi: 10.1093/bmb/lds024

Girós, A., Morante, J., Gil-Sanz, C., Fairén, A., and Costell, M. (2007). Perlecan controls neurogenesis in the developing telencephalon. BMC Dev. Biol. 7:29. doi: 10.1186/1471-213X-7-29

Gonçalves, J. T., Schafer, S. T., and Gage, F. H. (2016). Adult neurogenesis in the hippocampus: from stem cells to behavior. Cell 167, 897-914. doi: 10.1016/j.cell.2016.10.021

Grobe, K., and Esko, J. D. (2002). Regulated translation of heparan sulfate Nacetylglucosamine $\mathrm{N}$-deacetylase/n-sulfotransferase isozymes by structured 5'untranslated regions and internal ribosome entry sites. J. Biol. Chem. 277, 30699-30706. doi: 10.1074/jbc.M111904200

Hagihara, K., Watanabe, K., Chun, J., and Yamaguchi, Y. (2000). Glypican-4 is an FGF2-binding heparan sulfate proteoglycan expressed in neural precursor cells. Dev. Dyn. 219, 353-367. doi: 10.1002/1097-0177(2000)9999:9999 <::AIDDVDY1059>3.0.CO;2-\#

Hao, L., Zou, Z., Tian, H., Zhang, Y., Zhou, H., and Liu, L. (2014). Stem cell-based therapies for ischemic stroke. Biomed Res. Int. 2014:468748. doi: $10.1155 / 2014 / 468748$

Haupt, L. M., Murali, S., Mun, F. K., Teplyuk, N., Mei, L. F., Stein, G. S., et al. (2009). The heparan sulfate proteoglycan (HSPG) glypican-3 mediates commitment of MC3T3-E1 cells toward osteogenesis. J. Cell. Physiol. 220, 780-791. doi: 10.1002/jcp.21825

Helledie, T., Dombrowski, C., Rai, B., Lim, Z. X., Hin, I. L., Rider, D. A., et al. (2012). Heparan sulfate enhances the self-renewal and therapeutic potential of mesenchymal stem cells from human adult bone marrow. Stem Cells Dev. 21, 1897-1910. doi: 10.1089/scd.2011.0367

Hsueh, Y. P., and Sheng, M. (1999). Regulated expression and subcellular localization of syndecan heparan sulfate proteoglycans and the syndecanbinding protein CASK/LIN-2 during rat brain development. J. Neurosci. 19, 7415-7425.

Hu, H.-T., Umemori, H., and Hsueh, Y.-P. (2016). Postsynaptic SDC2 induces transsynaptic signaling via FGF22 for bidirectional synaptic formation. Sci. Rep. 6:33592. doi: 10.1038/srep33592

Huang, M. L., Smith, R. A. A., Trieger, G. W., and Godula, K. (2014). Glycocalyx remodeling with proteoglycan mimetics promotes neural specification in embryonic stem cells. J. Am. Chem. Soc. 136, 10565-10568 doi: 10.1021/ja505012a

Hunsberger, J. G., Rao, M., Kurtzberg, J., Bulte, J. W. M., Atala, A., LaFerla, F. M., et al. (2016). Accelerating stem cell trials for Alzheimer's disease. Lancet Neurol. 15, 219-230. doi: 10.1016/S1474-4422(15)00332-4

Inatani, M., Irie, F., Plump, A. S., Tessier-Lavigne, M., and Yamaguchi, Y. (2003). Mammalian brain morphogenesis and midline axon guidance require heparan sulfate. Science 302, 1044-1046. doi: 10.1126/science. 1090497

Jen, Y.-H. L., Musacchio, M., and Lander, A. D. (2009). Glypican-1 controls brain size through regulation of fibroblast growth factor signaling in early neurogenesis. Neural Dev. 4:33. doi: 10.1186/1749-8104-4-33

Jeong, S. W., Chu, K., Jung, K. H., Kim, S. U., Kim, M., and Roh, J. K. (2003). Human neural stem cell transplantation promotes functional recovery in rats with experimental intracerebral hemorrhage. Stroke 34, 2258-2263. doi: 10.1161/01.STR.0000083698.20199.1F

Johnson, C. E., Crawford, B. E., Stavridis, M., Ten Dam, G., Wat, A. L., Rushton, G., et al. (2007). Essential alterations of heparan sulfate during the differentiation of embryonic stem cells to Sox1-enhanced green fluorescent protein-expressing neural progenitor cells. Stem Cells 25, 1913-1923. doi: 10.1634/stemcells.2006-0445

Jones, L. L., Yamaguchi, Y., Stallcup, W. B., and Tuszynski, M. H. (2002). NG2 is a major chondroitin sulfate proteoglycan produced after spinal cord injury and is expressed by macrophages and oligodendrocyte progenitors. J. Neurosci. 22, 2792-2803.

Kalus, I., Rohn, S., Puvirajesinghe, T. M., Guimond, S. E., Eyckerman-Kölln, P. J., Ten Dam, G., et al. (2015). Sulf1 and Sulf2 differentially modulate heparan sulfate proteoglycan sulfation during postnatal cerebellum development: evidence for neuroprotective and neurite outgrowth promoting functions. PLOS ONE 10:e0139853. doi: 10.1371/journal.pone. 0139853

Kalus, I., Salmen, B., Viebahn, C., von Figura, K., Schmitz, D., D’Hooge, R., et al. (2009). Differential involvement of the extracellular 6-O-endosulfatases Sulf1 and Sulf 2 in brain development and neuronal and behavioural plasticity. J. Cell. Mol. Med. 13, 4505-4521. doi: 10.1111/j.1582-4934.2008.00558.x

Kerever, A., Mercier, F., Nonaka, R., De Vega, S., Oda, Y., Zalc, B., et al. (2014). Perlecan is required for FGF-2 signaling in the neural stem cell niche. Stem Cell Res. 12, 492-505. doi: 10.1016/j.scr.2013.12.009

Kim, S. U., and de Vellis, J. (2009). Stem cell-based cell therapy in neurological diseases: a review. J. Neurosci. Res. 87, 2183-2200. doi: 10.1002/jnr.22054

Kirn-Safran, C., Farach-Carson, M. C., and Carson, D. D. (2009). Multifunctionality of extracellular and cell surface heparan sulfate proteoglycans. Cell. Mol. Life Sci. 66, 3421-3434. doi: 10.1007/s00018-009-0096-1

Knox, S. M., and Whitelock, J. M. (2006). Perlecan: how does one molecule do so many things? Cell. Mol. Life Sci. 63, 2435-2445. doi: 10.1007/s00018-006-6162-z

Ko, J. S., Pramanik, G., Um, J. W., Shim, J. S., Lee, D., Kim, K. H., et al. (2015). PTP $\sigma$ functions as a presynaptic receptor for the glypican-4/LRRTM4 complex and is essential for excitatory synaptic transmission. Proc. Natl. Acad. Sci. U.S.A. 112, 1874-1879. doi: 10.1073/pnas.1410138112

Korotchenko, S., Cingolani, L. A., Kuznetsova, T., Bologna, L. L., Chiappalone, M., and Dityatev, A. (2014). Modulation of network activity and induction of homeostatic synaptic plasticity by enzymatic removal of heparan sulfates. Philos. Trans. R. Soc. Lond. Ser. B Biol. Sci. 369:20140134. doi: 10.1098/rstb.2014.0134

Kraushaar, D. C., Dalton, S., and Wang, L. (2013). Heparan sulfate: a key regulator of embryonic stem cell fate. Biol. Chem. 394, 741-751. doi: 10.1515/hsz-2012-0353

Kuhn, H. G., Eisch, A. J., Spalding, K., and Peterson, D. A. (2016). Detection and phenotypic characterization of adult neurogenesis. Cold Spring Harb. Perspect. Biol. 8:a025981. doi: 10.1101/cshperspect.a025981

Kunath, T., Saba-El-Leil, M. K., Almousailleakh, M., Wray, J., Meloche, S., and Smith, A. (2007). FGF stimulation of the Erk1/2 signalling cascade triggers transition of pluripotent embryonic stem cells from self-renewal to lineage commitment. Development 134, 2895-2902. doi: 10.1242/dev.02880

Kurosawa, H. (2007). Methods for inducing embryoid body formation: in vitro differentiation system of embryonic stem cells. J. Biosci. Bioeng. 103, 389-398. doi: $10.1263 /$ jbb.103.389 
Law, S., and Chaudhuri, S. (2013). Mesenchymal stem cell and regenerative medicine: regeneration versus immunomodulatory challenges. Am. J. Stem Cells 2, 22-38.

Lee, H. J., Kim, K. S., Kim, E. J., Choi, H. B., Lee, K. H., Park, I. H., et al. (2007). Brain transplantation of immortalized human neural stem cells promotes functional recovery in mouse intracerebral hemorrhage stroke model. Stem Cells 25, 1204-1212. doi: 10.1634/stemcells.2006-0409

Lindahl, U., Kusche-Gullberg, M., and Kjellén, L. (1998). Regulated diversity of heparan sulfate. J. Biol. Chem. 273, 24979-24982. doi: 10.1074/jbc.273.39.24979

Litwack, E. D., Ivins, J. K., Kumbasar, A., Paine-Saunders, S., Stipp, C. S., and Lander, A. D. (1998). Expression of the heparan sulfate proteoglycan glypican-1 in the developing rodent. Dev. Dyn. 211, 72-87. doi: 10.1002/(SICI) 1097-0177(199801)211:1<72::AID-AJA7> 3.0.CO;2-4

Liu, Q., Lyu, Z., Yu, Y., Zhao, Z. A., Hu, S., Yuan, L., et al. (2017). Synthetic glycopolymers for highly efficient differentiation of embryonic stem cells into neurons: lipo- or not? ACS Appl. Mater. Interfaces 9, 11518-11527. doi: $10.1021 /$ acsami.7b01397

Liu, S.-P., Fu, R.-H., Huang, S.-J., Huang, Y.-C., Chen, S.-Y., Chang, C.-H., et al. (2013). Stem cell applications in regenerative medicine for neurological disorders. Cell Transplant. 22, 631-637. doi: 10.3727/096368912X655145

Lopes, C. C., Dietrich, C. P., and Nader, H. B. (2006). Specific structural features of syndecans and heparan sulfate chains are needed for cell signaling. Braz. J. Med. Biol. Res. 39, 157-167. doi: 10.1590/S0100-879X2006000200001

Ma, T. (2010). Mesenchymal stem cells: From bench to bedside. World J. Stem Cells 2:13. doi: $10.4252 /$ wjsc.v2.i2.13

McLaughlin, D., Karlsson, F., Tian, N., Pratt, T., Bullock, S. L., Wilson, V. A., et al. (2003). Specific modification of heparan sulphate is required for normal cerebral cortical development. Mech. Dev. 120, 1481-1488. doi: 10.1016/j.mod.2003.08.008

Mikami, T., and Kitagawa, H. (2016). Sulfated glycosaminoglycans: their distinct roles in stem cell biology. Glycoconj. J. doi: 10.1007/s10719-016-9732-9. [Epub ahead of print]. Available online at: https://link-springer-com.ezp01.library. qut.edu.au/journal/10719/onlineFirst/It

Mimura, S., Kimura, N., Hirata, M., Tateyama, D., Hayashida, M., Umezawa, A., et al. (2011). Growth factor-defined culture medium for human mesenchymal stem cells. Int. J. Dev. Biol. 55, 181-187. doi: 10.1387/ijdb.103232sm

Ming, G. L., and Song, H. (2011). Adult neurogenesis in the mammalian brain: significant answers and significant questions. Neuron 70, 687-702. doi: 10.1016/j.neuron.2011.05.001

Minge, D., Senkov, O., Kaushik, R., Herde, M. K., Tikhobrazova, O., Wulff, A. B., et al. (2017). Heparan sulfates support pyramidal cell excitability, synaptic plasticity, and context discrimination. Cereb. Cortex 27, 903-918. doi: 10.1093/cercor/bhx003

Montzka, K., Lassonczyk, N., Tschöke, B., Neuss, S., Führmann, T., Franzen, R., et al. (2009). Neural differentiation potential of human bone marrow-derived mesenchymal stromal cells: misleading marker gene expression. BMC Neurosci. 10:16. doi: 10.1186/1471-2202-10-16

Nagoshi, N., and Okano, H. (2017). Applications of induced pluripotent stem cell technologies in spinal cord injury. J. Neurochem. 141, 848-860. doi: $10.1111 /$ jnc. 13986

Nairn, A. V., Kinoshita-Toyoda, A., Toyoda, H., Xie, J., Harris, K., Dalton, S., et al. (2007). Glycomics of proteoglycan biosynthesis in murine embryonic stem cell differentiation. J. Proteome Res. 6, 4374-4387. doi: 10.1021/pr070446f

Nakamura, R., Nakamura, F., and Fukunaga, S. (2015). Diverse functions of perlecan in central nervous system cells in vitro. Anim. Sci. J. 86, 904-911. doi: $10.1111 / a s j .12376$

Nam, H., Lee, K.-H., Nam, D.-H., and Joo, K. M. (2015). Adult human neural stem cell therapeutics: current developmental status and prospect. World J. Stem Cells 7, 126-136. doi: 10.4252/wjsc.v7.i1.126

Neirinckx, V., Rogister, B., Coste, C., and Wislet-Gendebien, S. (2013). "Neural fate of mesenchymal stem cells and neural crest stem cells: which ways to get neurons for cell therapy purpose?," Trends in Cell Signaling Pathways in Neuronal Fate Decision, ed S. Wislet-Gendebien (Rijeka: INTECH Open Access Publisher), 327-358.

Nurcombe, V., Ford, M. D., Wildschut, J. A., and Bartlett, P. F. (1993). Developmental regulation of neural response to FGF-1 and FGF-2 by heparan sulfate proteoglycan. Science 260, 103-106.
Oikari, L., Griffiths, L., and Haupt, L. (2014). The current state of play in human neural stem cell models: what we have learnt from the rodent. OA Stem Cells 2:7.

Oikari, L. E., Okolicsanyi, R. K., Griffiths, L. R., and Haupt, L. M. (2016a). Data defining markers of human neural stem cell lineage potential. Data Brief. 7, 206-215. doi: 10.1016/j.dib.2016.02.030

Oikari, L. E., Okolicsanyi, R. K., Qin, A., Yu, C., Griffiths, L. R., and Haupt, L. M. (2016b). Cell surface heparan sulfate proteoglycans as novel markers of human neural stem cell fate determination. Stem Cell Res. 16, 92-104. doi: 10.1016/j.scr.2015.12.011

Okolicsanyi, R. K., Camilleri, E. T., Oikari, L. E., Yu, C., Cool, S. M., van Wijnen, A. J., et al. (2015). Human mesenchymal stem cells retain multilineage differentiation capacity including neural marker expression after extended in vitro expansion. PLOS ONE 10:e0137255. doi: 10.1371/journal.pone. 0137255

Okolicsanyi, R. K., Griffiths, L. R., and Haupt, L. M. (2014). Mesenchymal stem cells, neural lineage potential, heparan sulfate proteoglycans and the matrix. Dev. Biol. 388, 1-10. doi: 10.1016/j.ydbio.2014.01.024

Palma, V., Carrasco, H., Reinchisi, G., Olivares, G., Faunes, F., and Larraín, J. (2011). SHh activity and localization is regulated by perlecan. Biol. Res. 44, 63-67. doi: 10.4067/S0716-97602011000100008

Pickford, C. E., Holley, R. J., Rushton, G., Stavridis, M. P., Ward, C. M., and Merry, C. L. (2011). Specific glycosaminoglycans modulate neural specification of mouse embryonic stem cells. Stem Cells 29, 629-640. doi: 10.1002/ stem. 610

Poulain, F. E., and Yost, H. J. (2015). Heparan sulfate proteoglycans: a sugar code for vertebrate development? Development 142, 3456-3467. doi: $10.1242 / \mathrm{dev} .098178$

Pratt, T., Conway, C. D., Tian, N. M., Price, D. J., and Mason, J. O. (2006). Heparan sulphation patterns generated by specific heparan sulfotransferase enzymes direct distinct aspects of retinal axon guidance at the optic chiasm. J. Neurosci. 26, 6911-6923. doi: 10.1523/JNEUROSCI.0505-06.2006

Properzi, F., Lin, R., Kwok, J., Naidu, M., Van Kuppevelt, T. H., Ten Dam, G. B., et al. (2008). Heparan sulphate proteoglycans in glia and in the normal and injured CNS: expression of sulphotransferases and changes in sulphation. Eur. J. Neurosci. 27, 593-604. doi: 10.1111/j.1460-9568.2008. 06042.x

Pulsipher, A., Griffin, M. E., Stone, S. E., and Hsieh-Wilson, L. C. (2015). Longlived glycan engineering to direct stem cell fate. Angew. Chem. Int. Ed. Engl. 54, 1466-1470. doi: 10.1002/anie.201409258

Rapraeger, A. C., and Ott, V. L. (1998). Molecular interactions of the syndecan core proteins. Curr. Opin. Cell Biol. 10, 620-628. doi: 10.1016/S0955-0674(98)80038-0

Riess, P., Zhang, C., Saatman, K. E., Laurer, H. L., Longhi, L. G., Raghupathi, R., et al. (2002). Transplanted neural stem cells survive, differentiate, and improve neurological motor function after experimental traumatic brain injury. Neurosurgery 51, 1043-1052; discussion:52-54. doi: 10.1227/01.NEU.0000027826.68845.CF

Rolfe, A., and Sun, D. (2015). "Stem cell therapy in brain trauma: implications for repair and regeneration of injured brain in experimental TBI models," in Brain Neurotrauma: Molecular, Neuropsychological, and Rehabilitation Aspects, ed F. H. Kobeissy (Boca Raton, FL: CRC Press), 587-596.

Sadan, O., Melamed, E., and Offen, D. (2009). Bone-marrow-derived mesenchymal stem cell therapy for neurodegenerative diseases. Expert Opin. Biol. Ther. 9, 1487-1497. doi: 10.1517/14712590903321439

Sakiyama-Elbert, S. E. (2014). Incorporation of heparin into biomaterials. Acta Biomater. 10, 1581-1587. doi: 10.1016/j.actbio.2013.08.045

Sarrazin, S., Lamanna, W. C., and Esko, J. D. (2011). Heparan sulfate proteoglycans. Cold Spring Harb. Perspect. Biol. 3:a004952. doi: 10.1101/cshperspect.a004952

Siddiqui, T. J., Tari, P. K., Connor, S. A., Zhang, P., Dobie, F. A. She, K., et al. (2013). An LRRTM4-HSPG complex mediates excitatory synapse development on dentate gyrus granule cells. Neuron 79, 680-695. doi: 10.1016/j.neuron.2013.06.029

Smith, R. A., Meade, K., Pickford, C. E., Holley, R. J., and Merry, C. L. (2011). Glycosaminoglycans as regulators of stem cell differentiation. Biochem. Soc. Trans. 39, 383-387. doi: 10.1042/BST0390383 
Song, H. H., and Filmus, J. (2002). The role of glypicans in mammalian development. Biochim. Biophys. Acta 1573, 241-246. doi: 10.1016/S0304-4165(02)00390-2

Srijaya, T. C., Ramasamy, T. S., and Kasim, N. H. A. (2014). Advancing stem cell therapy from bench to bedside: lessons from drug therapies. J. Transl. Med. 12, 243. doi: 10.1186/s12967-014-0243-9

Stavridis, M. P., Lunn, J. S., Collins, B. J., and Storey, K. G. (2007). A discrete period of FGF-induced Erk1/2 signalling is required for vertebrate neural specification. Development 134, 2889-2894. doi: 10.1242/dev.02858

Stringer, S. E., Mayer-Proschel, M., Kalyani, A., Rao, M., and Gallagher, J. T. (1999). Heparin is a unique marker of progenitors in the glial cell lineage. J. Biol. Chem. 274, 25455-25460. doi: 10.1074/jbc.274.36.25455

Studer, L., Tabar, V., and McKay, R. (1998). Transplantation of expanded mesencephalic precursors leads to recovery in parkinsonian rats. Nat. Neurosci. 1, 290-295.

Sugahara, K., and Kitagawa, H. (2002). Heparin and heparan sulfate biosynthesis. IUBMB Life 54, 163-175. doi: 10.1080/15216540214928

Sugaya, N., Habuchi, H., Nagai, N., Ashikari-Hada, S., and Kimata, K. (2008). 6-O-sulfation of heparan sulfate differentially regulates various fibroblast growth factor-dependent signalings in culture. J. Biol. Chem. 283, 10366-10376. doi: 10.1074/jbc.M705948200

Takahashi, K., Tanabe, K., Ohnuki, M., Narita, M., Ichisaka, T., Tomoda, K., et al. (2007). Induction of pluripotent stem cells from adult human fibroblasts by defined factors. Cell 131, 861-872. doi: 10.1016/j.cell.2007. 11.019

Tamm, C., Kjellén, L., and Li, J.-P. (2012). Heparan sulfate biosynthesis enzymes in embryonic stem cell biology. J. Histochem. Cytochem. 60, 943-949. doi: 10.1369/0022155412465090

Tsang, K. Y., Cheung, M. C., Chan, D., and Cheah, K. S. (2010). The developmental roles of the extracellular matrix: beyond structure to regulation. Cell Tissue Res. 339, 93-110. doi: 10.1007/s00441-009-0893-8

Urbán, N., and Guillemot, F. (2014). Neurogenesis in the embryonic and adult brain: same regulators, different roles. Front. Cell. Neurosci. 8:396. doi: 10.3389/fncel.2014.00396

van Velthoven, C. T., Kavelaars, A., van Bel, F., and Heijnen, C. J. (2009). Regeneration of the ischemic brain by engineered stem cells: fuelling endogenous repair processes. Brain Res. Rev. 61, 1-13. doi: 10.1016/j.brainresrev.2009.03.003

Venugopal, C., Chandanala, S., Prasad, H. C., Nayeem, D., Bhonde, R. R., and Dhanushkodi, A. (2017). Regenerative therapy for hippocampal degenerative diseases: lessons from preclinical studies. J. Tissue Eng. Regen. Med. 11, 321-333. doi: 10.1002/term.2052

Wagner, W., Ho, A. D., and Zenke, M. (2010). Different facets of aging in human mesenchymal stem cells. Tissue Eng. Part B Rev. 16, 445-453. doi: 10.1089/ten.teb.2009.0825

Wang, M., Liu, X., Lyu, Z., Gu, H., Li, D., and Chen, H. (2017). Glycosaminoglycans (GAGs) and GAG mimetics regulate the behavior of stem cell differentiation. Colloids Surf. B Biointerfaces 150, 175-182. doi: 10.1016/j.colsurfb.2016.11.022

Wang, M., Lyu, Z., Chen, G., Wang, H., Yuan, Y., Ding, K., et al. (2015). A new avenue to the synthesis of GAG-mimicking polymers highly promoting neural differentiation of embryonic stem cells. Chem. Commun. 51, 15434-15437. doi: 10.1039/C5CC06944K
Wang, Q., Matsumoto, Y., Shindo, T., Miyake, K., Shindo, A., Kawanishi, M., et al. (2006). Neural stem cells transplantation in cortex in a mouse model of Alzheimer's disease. J. Med. Invest. 53, 61-69. doi: 10.2152/jmi.53.61

Wang, Q., Yang, L., Alexander, C., and Temple, S. (2012). The niche factor syndecan-1 regulates the maintenance and proliferation of neural progenitor cells during mammalian cortical development. PLOS ONE 7:e42883. doi: 10.1371/journal.pone.0042883

Wang, S. P., Wang, Z. H., Peng, D. Y., Li, S. M., Wang, H., and Wang, X. H. (2012). Therapeutic effect of mesenchymal stem cells in rats with intracerebral hemorrhage: reduced apoptosis and enhanced neuroprotection. Mol. Med. Rep. 6, 848-854. doi: 10.3892/mmr.2012.997

Willerth, S. M., Rader, A., and Sakiyama-Elbert, S. E. (2008). The effect of controlled growth factor delivery on embryonic stem cell differentiation inside of fibrin scaffolds. Stem Cell Res. 1, 205-218. doi: 10.1016/j.scr.2008.05.006

Winkler, S., Stahl, R. C., Carey, D. J., and Bansal, R. (2002). Syndecan3 and perlecan are differentially expressed by progenitors and mature oligodendrocytes and accumulate in the extracellular matrix. J. Neurosci. Res. 69, 477-487. doi: 10.1002/jnr.10311

Xian, X., Gopal, S., and Couchman, J. R. (2010). Syndecans as receptors and organizers of the extracellular matrix. Cell Tissue Res. 339, 31-46. doi: 10.1007/s00441-009-0829-3

Yamada, T., Kerever, A., Yoshimura, Y., Suzuki, Y., Nonaka, R., Higashi, K., et al. (2017). Heparan sulfate alterations in extracellular matrix structures and fibroblast growth factor-2 signaling impairment in the aged neurogenic niche. J. Neurochem. 142, 534-544. doi: 10.1111/jnc.14081

Yamaguchi, Y. (2001). Heparan sulfate proteoglycans in the nervous system: their diverse roles in neurogenesis, axon guidance, and synaptogenesis. Semin. Cell Dev. Biol. 12, 99-106. doi: 10.1006/scdb.2000.0238

Yayon, A., Klagsbrun, M., Esko, J. D., Leder, P., and Ornitz, D. M. (1991). Cell surface, heparin-like molecules are required for binding of basic fibroblast growth factor to its high affinity receptor. Cell 64, 841-848. doi: 10.1016/0092-8674(91)90512-W

Ying, Q.-L., Stavridis, M., Griffiths, D., Li, M., and Smith, A. (2003). Conversion of embryonic stem cells into neuroectodermal precursors in adherent monoculture. Nat. Biotechnol. 21, 183-186. doi: 10.1038/nbt780

Zhang, S.-C., Wernig, M., Duncan, I. D., Brüstle, O., and Thomson, J. A. (2001). In vitro differentiation of transplantable neural precursors from human embryonic stem cells. Nat. Biotechnol. 19, 1129-1133. doi: $10.1038 /$ nbt1201-1129

Zhao, C., Deng, W., and Gage, F. H. (2008). Mechanisms and functional implications of adult neurogenesis. Cell 132, 645-660. doi: 10.1016/j.cell.2008.01.033

Conflict of Interest Statement: The authors declare that the research was conducted in the absence of any commercial or financial relationships that could be construed as a potential conflict of interest.

Copyright (C) 2017 Yu, Griffiths and Haupt. This is an open-access article distributed under the terms of the Creative Commons Attribution License (CC BY). The use, distribution or reproduction in other forums is permitted, provided the original author(s) or licensor are credited and that the original publication in this journal is cited, in accordance with accepted academic practice. No use, distribution or reproduction is permitted which does not comply with these terms. 